\title{
Optimasi Waktu Maserasi untuk Manggis (Garcinia mangostana L.) Rind Menggunakan Pelarut Etil Asetat
}

Ni Putu Ayu Dewi Wijayanti*, Dewi, L.P.M.K., Astuti, K.W AND Fitri, N.P.E.

Department of Pharmacy, Faculty of Mathematics and Natural Sciences, Udayana University

Corresponding author: dewi_wijayanti@unud.ac.id

\begin{abstract}
Background: Maceration is a non-heating extraction method the result of which is affected by the type of solvent and the maceration time. Objective: To get the higher alpha-mangostin concentration (Garcinia mangostana L.) rind that was macerated using ethyl acetate solvent and to determine the optimum maceration time needed to produce high concentration of alpha-mangostin. Methods: the mangosteen rind was macerated using ethyl acetate with the variation of the maceration time of 6, 12, 24 and 48 hours. The extract was then dried using the freeze drying method. The optimum maceration time was determined by looking at the highest concentration of alpha-mangostin from each extraction time using $T L C$-densitometry method with a silica gel stationary phase of $G F_{254}$ and a mobile phase of chloroformmethanol (10:0.1, v/v). Results: The results showed that the difference in the maceration time can affect the concentration of alpha-mangostin compound contained in the extract. Conclusions: It was found out that the 24-hour maceration time produced the highest concentration of alpha-mangostin that is 3031.34 $n g$.
\end{abstract}

Keywords: maceration time, alpha-mangostin, ethyl acetate

\begin{abstract}
Abstrak
Pendahuluan: Maserasi merupakan metode ekstraksi tanpa pemanasan dimana hasilnya dipengaruhi oleh jenis pelarut serta waktu maserasi. Tujuan penelitian: Dalam penelitian ini dilakukan maserasi kulit buah manggis (Garcinia mangostana L.) menggunakan pelarut etil asetat untuk mengekstraksi senyawa alfa mangosteen namun belum diketahui berapa lama waktu maserasi optimum yang dibutuhkan agar dihasilkan kadar alfa mangosten yang tinggi. Untuk itu dilakukan optimasi waktu maserasi agar diperoleh hasil tersebut. Metode: Kulit buah manggis dimaserasi menggunakan etil asetat dengan memvariasikan waktu maserasi selama 6, 12, 24 dan 48 jam. Ekstrak kemudian dikeringkan dengan metode freeze drying. Waktu maserasi optimum ditentukan berdasarkan kadar alfa mangostin tertinggi dari masing-masing waktu ekstraksi menggunakan metode KLT-Spektrofotodensitometri dengan fase diam silika gel $\mathrm{GF}_{254}$ dan fase gerak kloroform : metanol $(10: 0,1) \mathrm{v} / \mathrm{v}$. Hasil: Hasil penelitian menunjukkan bahwa variasi waktu maserasi dapat mempengaruhi kadar alfa mangostin yang terdapat dalam ekstrak. Kesimpulan: Waktu maserasi selama 24 jam menghasilkan kadar alfa mangosten tertinggi yakni sebesar 3031,34 ng.
\end{abstract}

Kata Kunci: waktu maserasi, alfa mangostin, etil asetat 


\section{Pendahuluan}

Kandungan metabolit sekunder dalam kulit buah manggis (Garcinia mangostana L.) yaitu xanthon, mangostin, garsinon, flavonoid dan tannin. Senyawa xanton yang terkandung dalam kulit buah manggis diantaranya alfa mangostin, beta mangostin, gamma mangostin dan methoxy- $\beta$-mangostin (Chaverri et al., 2008).

Alfa mangostin dapat diambil atau dipisahkan dari kulit buah manggis melalui proses yang disebut ekstraksi (DepKes RI, 1986). Salah satu metode yang digunakan dalam ekstraksi adalah metode maserasi yang dapat dilakukan dengan merendam sampel selama 4-10 hari, menggunakan pelarut yang sesuai, tanpa adanya pemanasan (Voight, 1995). Faktor lain yang dapat mempengaruhi proses maserasi diantaranya pemilihan jenis pelarut serta lama waktu maserasi. Etil asetat digunakan dalam proses maserasi kulit buah manggis karena senyawa yang akan diekstraksi adalah alfa mangostin yang bersifat semi polar. Etil asetat merupakan pelarut yang bersifat semi polar dengan konstanta dielektrik sebesar 6 .

Yeo et al. (2014) telah melakukan penelitian mengenai efektifitas waktu maserasi terhadap aktivitas antimikroba dari buah pare (Momordica charantia L.). Variasi waktu yang digunakan dalam penelitian tersebut adalah 6, 12, 24 dan 48 jam dengan pelarut yang berbedabeda diantaranya heksan, petroleum eter, etil asetat, aseton, etanol dan air panas. Hasil yang diperoleh menunjukkan bahwa waktu maserasi buah pare bertanggung jawab terhadap jenis dan konsentrasi dari senyawa aktif yang mampu terekstraksi (Yeo et al. 2014). Dalam penelitian ini dilakukan maserasi kulit buah manggis (Garcinia mangostana L.) menggunakan pelarut etil asetat untuk mengekstraksi senyawa alfa mangosteen namun belum diketahui berapa lama waktu maserasi optimum yang dibutuhkan agar dihasilkan kadar alfa mangosten yang tinggi. Untuk itu dilakukan optimasi waktu maserasi agar diperoleh hasil tersebut.

\section{BAHAN DAN METODE \\ Bahan Penelitian}

Kulit buah manggis yang digunakan dalam sebagai sampel dalam penelitian ini diperoleh dari Desa Luwus, Kecamatan Baturiti, Kabupaten Tabanan, Bali. Pelarut yang digunakan yaitu etil asetat (Asian chemical), metanol (Asian chemical), kloroform (Asian chemical), standar baku alpha mangostin (Sigma), plat silika gel $60 \mathrm{GF}_{254}$.

\section{Pengumpulan dan Pengolahan Simplisia}

Sampel dikumpulkan secara purposive. Sampel simplisia yang terkumpul kemudian diidentifikasi di Pusat Penelitian Determinasi Kebun Raya Eka Karya Bedugul, Tabanan, Bali. Simplisia dicuci hingga bersih, kemudian dikeringkan pada suhu ruang, setelah kering simplisia diperkecil ukuran partikelnya menggunakan blender dan diayak. Hasil ayakan dikeringkan dalam oven dengan suhu $40^{\circ} \mathrm{C}$.

\section{Penetapan Kadar Air Simplisia Kulit Buah Manggis (Garcinia mangostana L.)}

Penetapan kadar air simplisia kulit buah manggis dilakukan dengan metode gravimetri. Ditimbang botol timbang beserta tutupnya yang telah dikeringkan dalam oven dengan suhu $105^{\circ} \mathrm{C}$ selama 30 menit dan didinginkan dalam desikator. Kemudian ditimbang 1 gram simplisia kulit buah manggis dalam botol timbang kemudian dioven dengan suhu $105^{\circ} \mathrm{C}$ selama 30 menit dengan tutup terbuka. Didinginkan dalam desikator dan ditimbang kembali. Penetapan kadar air dilakukan hingga diperoleh perbedaan sampai selisih dua penimbangan kadar air tidak lebih dari $0,25 \%$. Pekerjaan ini diulang sebanyak dua kali (Depkes RI, 1995).

\section{Optimasi Waktu maserasi}

Kulit buah manggis (Garcinia mangostana L.) yang telah diserbuk, didefating dengan pelarut n-Heksana untuk menghilangkan kandungan senyawa yang bersifat nonpolar dari kulit buah manggis. Ampas serbuk hasil defating kemudian diekstraksi menggunakan pelarut etil asetat pada 4 bejana maserasi yang berbeda. Variasi waktu maserasi yang digunakan adalah 6, 12, 24 dan 48 jam dengan perbandingan serbuk pelarut etil asetat $1: 10 \mathrm{~b} / \mathrm{v}$. Ampas yang diperoleh diremaserasi menggunakan etil asetat dengan perbandingan $1: 4 \mathrm{~b} / \mathrm{v}$ selama 30 menit sebanyak 3 kali. Penguapan pelarut maserasi dilakukan dengan rotary evaporator pada suhu $45^{\circ}$ hingga diperoleh ekstrak kental. Ekstrak kental yang diperoleh dikeringkan dengan metode freeze drying.

\section{Penetapan Kadar}

\section{Pembuatan larutan sampel}

Ditimbang 200,0 mg ekstrak kemudian dimasukkan ke dalam botol vial, dilarutkan dengan pelarut etil asetat 
hingga volumenya $2 \mathrm{~mL}$ dan disaring. Ekstrak yang diperoleh kemudian diencerkan kembali dengan perbandingan 1:100 v/v (larutan sampel).

\section{Pengukuran Kadar Alfa mangostin Ekstrak Kulit Buah Manggis}

Seri standar baku alfa mangostin dibuat dari larutan standar konsentrasi $100 \mu \mathrm{g} / \mathrm{mL}$. Larutan standar ditotolkan sebanyak $1 \mu \mathrm{L}, 4 \mu \mathrm{L}, 8 \mu \mathrm{L}$ dan $12 \mu \mathrm{L}, 16 \mu \mathrm{L}$ dan $20 \mu \mathrm{L}$. Larutan sampel ditotolkan sebanyak $4 \mu \mathrm{L}$. Plat dielusi dengan fase gerak kloroform : metanol $(10: 0,1 \mathrm{v} / \mathrm{v})$ dengan jarak pengembangan $8 \mathrm{~cm}$. Spot diamati di bawah sinar UV 254. AU alpha mangostin diukur dengan densitometer pada panjang gelombang $320 \mathrm{~nm}$. Kadar alfa mangostin dalam sampel dihitung dengan persamaan regresi linier dari larutan standar alpha mangostin. Pengukuran masing-masing larutan dilakukan dengan replikasi sebanyak tiga kali.

\section{hasil Dan Pembahasan}

\section{Pengumpulan dan pengolahan simplisia}

Hasil identifikasi yang dilakukan di Pusat Penelitian Determinasi Kebun Raya Eka Karya Bedugul, menunjukkan bahwa tumbuhan ini termasuk ke dalam suku Clusiaceae, marga Garcinia dan spesies Garcinia mangostana $\mathrm{L}$.

\section{Penetapan Kadar Air Simplisia}

Kadar air simplisia kulit buah manggis yang diperoleh adalah $8,21 \pm 0,84 \%$, hasil tersebut menunjukkan bahwa kadar air pada serbuk simplisia kulit buah manggis (Garcinia mangostana L.) lebih rendah dari persyaratan kadar air maksimal yaitu 10\% (Depkes RI, 2010).

\section{Optimasi Waktu Maserasi Ekstrak Kulit Buah Manggis (Garcinia mangostana L.)}

Setelah dimaserasi dengan pelarut etil asetat diperoleh 4 sampel dengan variasi waktu maserasi diantaranya 6,12 , 24 dan 48 jam, dengan rendemen $9,178 \%, 9,865 \%$, $11,201 \%$ dan $11,834 \%$. Rendemen ekstrak kering tertinggi dihasilkan oleh waktu maserasi selama 48 jam. Dari hasil tersebut dapat dilihat bahwa, semakin lama waktu maserasi, maka senyawa yang terekstrak menjadi semakin banyak. Hal ini disebabkan oleh waktu kontak antara bahan dan pelarut menjadi bertambah lama sehingga kemampuan pelarut untuk mengambil flavonoid dalam bahan semakin optimal pula (Koirewoa, 2012).

\section{Penetapan Kadar Alfa mangostin Hasil Optimasi Waktu Maserasi}

Hasil pengamatan spektrum standar alfa mangostin dan larutan sampel ekstrak etanol $96 \%$ kulit buah manggis ditampilkan pada gambar 1

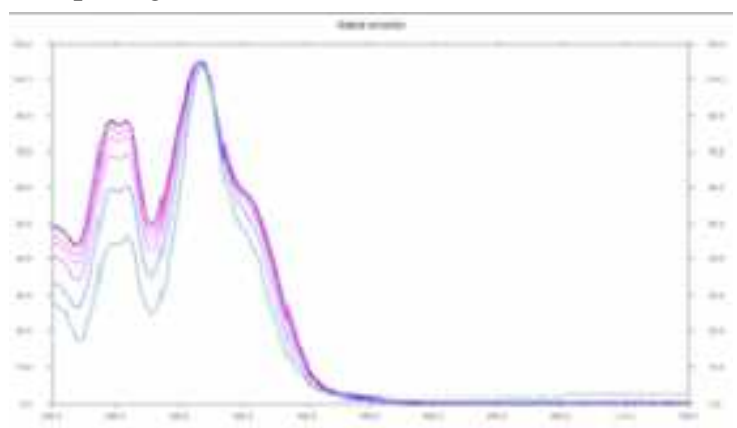

Gambar 1. Spektrum standar dan sampel ekstrak etanol $96 \%$ kulit buah manggis dengan $\lambda_{\text {maks }} 320 \mathrm{~nm}$.

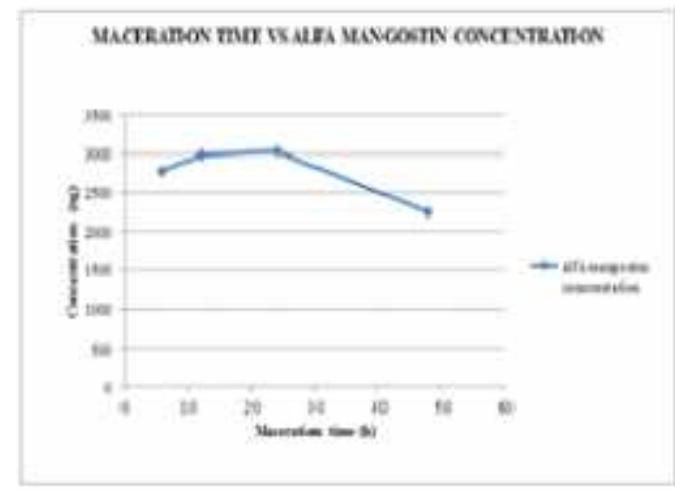

Gambar 2. Grafik hubungan antar waktu maserasi dengan kadar alfa mangostin dalam ekstrak kulit buah manggis.

Selanjutnya spot dideteksi pada panjang gelombang maksimumnya yaitu $320 \mathrm{~nm}$ untuk memperoleh nilai $\mathrm{AU}$ dari setiap seri dan sampel. Kadar alfa mangostin yang diperoleh dari variasi waktu maserasi 6,12, 24 dan 48 jam secara berturut-turut adalah 2773,67 ng, $2984 \mathrm{ng}, 3031,34$ ng dan 2239,4 ng. Penetapan kadar senyawa alfa mangostin yang terkandung dalam ekstrak dengan variasi waktu maserasi $6,12,24$ dan 48 jam dilakukan dengan membuat kurva kalibrasi dari larutan seri standar alfa mangostin dan diperoleh persamaan regresi linier yaitu $\mathrm{y}=$ $4272,1558 x+12112,9832$ dengan nilai koefisien regresi linier $(r)=0,99621$. 

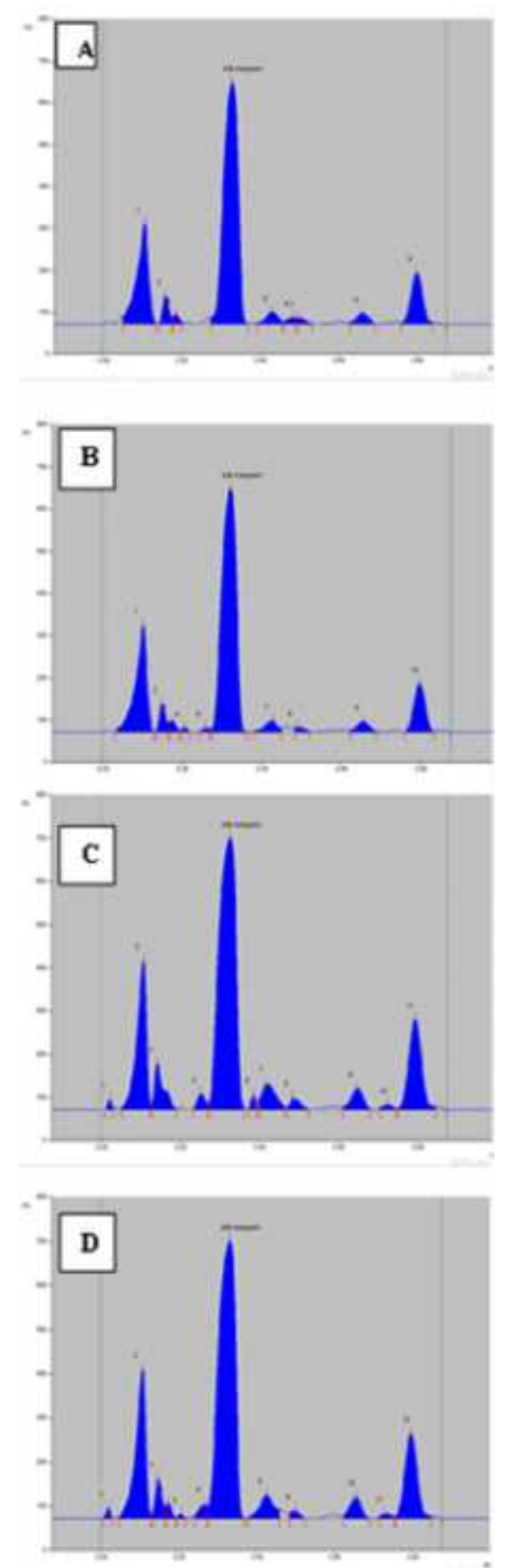

Gambar 3. Kromatogram senyawa alfa mangostin hasil optimasi waktu maserasi dengan variasi waktu maserasi selama 6 jam (A), 12 jam (B), 24 jam (C) dan 48 jam (D).

Gambar 3 menunjukkan bahwa variasi waktu maserasi dapat mempengaruhi kadar alfa mangostin yang terdapat dalam ekstrak. Penambahan waktu maserasi akan meningkatkan penetrasi pelarut ke dalam bahan. Kelarutan komponen dalam sampel secara perlahan sebanding dengan penambahan waktu maserasi, akan tetapi setelah mencapai waktu optimum jumlah komponen yang terambil dari bahan akan mengalami penurunan. Waktu maserasi dengan kadar alfa mangostin tertinggi dihasilkan pada maserasi selama 24 jam, dimana laju difusi senyawa alfa mangostin dari permukaan padatan ke pelarut sama besarnya dengan laju difusi senyawa alfa mangostin dari pelarut ke permukaan padatan sehingga konsentrasi alfa mangostin dalam pelarut sudah berada dalam kesetimbangan.

\section{KESIMPULAN}

Berdasarkan hasil penelitian waktu maserasi kulit buah manggis yang optimum adalah dengan perendaman selama 24 jam dengan kadar alfa mangostin pada spot adalah sebesar 3031,34 ng.

\section{UCAPAN TERIMA KASIH}

1. Lembaga Pebelitian dan Pengabdian kepada Masyarakat (LPPM) Universitas Udayana.

2. Fakultas Matematika dan Ilmu Pengetahuan Alam Universitas Udayana.

\section{Daftar Pustaka}

Chaverri, J.P., Noemi C. R., Morisol O. I., Jazmin M. and Perez R. 2008. Review Medical Properties of Mangosteen. Food and Chemical Toxicology. Vol. 46: 3227-3239.

Dachriyanus, Rezie, A. dan Regina A. 2014. Development and Validation of Thin Layer Chromatographic Method for Determination of $\alpha$-mangostin in Young Pericarp, Ripe Pericarp and Bark Extract of Garcinia mangostana L. Using TLC-Densitometry. Int. J. Res. Pharm. Sci. Vol. 5(4): 294-298.

DepKes RI. 1986. Sediaan Galenik. Jakarta: Departemen Kesehatan Republik Indonesia.

Koirewoa, Y. A., Fatimawali, W. I. Wiyono, 2012. Isolasi dan Identifikasi Senyawa Flavonoid dalam Daun Beluntas (Pluchea indica L.).Laporan Penelitian. FMIPA UNSRAT. Manado.

Voight, R. 1995. Buku Pelajaran Teknologi Farmasi. Edisi Kelima. Yogyakarta: Gadjah Mada University Press.

Yeo, Y.L., Yin Y.C., Chin H.L., Heng S.S., Wai S.Y. 2014. Effectiveness of Maceration Periods with Different Extraction Solvents on in-vitro Antimicrobial Activity from Fruit of Momordica charantia L. Journal of Applied Pharmaceutical Science.Vol. 4 (10): 016-020.niek SB,

M.Zainuddin, Junaidi Khotib. 2014. Biocompatable Composite As Gentamicin Delivery System for 
Osteomyelitis and Bone Regeneration, International Journal of Pharmacy and Pharmaceutical Sciencis.

Vol 6, Issue 3, p.223-226 